\title{
Diagnosis and Treatment of Community-Acquired Pneumonia
}

\author{
M. NAWAL LUTFIYYA, PH.D., ERIC HENLEY, M.D., M.P.H., and LINDA F. CHANG, PHARM.D., M.P.H., B.C.P.S. \\ University of Illinois College of Medicine at Rockford, Rockford, Illinois \\ STEPHANIE WESSEL REYBURN, M.D., M.P.H., Mayo School of Graduate Medical Education, Rochester, Minnesota
}

Patients with community-acquired pneumonia often present with cough, fever, chills, fatigue, dyspnea, rigors, and pleuritic chest pain. When a patient presents with suspected community-acquired pneumonia, the physician should first assess the need for hospitalization using a mortality prediction tool, such as the Pneumonia Severity Index, combined with clinical judgment. Consensus guidelines from several organizations recommend empiric therapy with macrolides, fluoroquinolones, or doxycycline. Patients who are hospitalized should be switched from parenteral antibiotics to oral antibiotics after their symptoms improve, they are afebrile, and they are able to tolerate oral medications. Clinical pathways are important tools to improve care and maximize cost-effectiveness in hospitalized patients. (Am Fam Physician 2006;73:442-50. Copyright (C) 2006 American Academy of Family Physicians.)

Members of various family medicine departments develop articles for "Practical Therapeutics." This article is one in a series coordinated by the Department of Family Medicine at the University of Illinois at Chicago College of Medicine, Chicago, III. Guest editor of the series is Eric Henley, M.D., M.P.H.

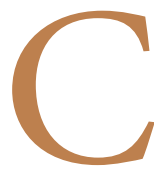

ommunity-acquired pneumonia $(\mathrm{CAP})$ is defined as pneumonia not acquired in a hospital or a long-term care facility. Despite the availability of potent new antimicrobials and effective vaccines, ${ }^{1}$ an estimated 5.6 million cases of CAP occur annually in the United States. ${ }^{2}$ The estimated total annual cost of health care for CAP in the United States is $\$ 8.4$ billion. $^{2}$ Table 1 presents an overview of CAP including definition, signs and symptoms, etiology, and risk factors.

\section{Epidemiology}

The epidemiology of CAP is unclear because few population-based statistics on the condition alone are available. The Centers for Disease Control and Prevention (CDC) combines pneumonia with influenza when collecting data on morbidity and mortality, although they do not combine them when collecting hospital discharge data. In 2001, influenza and pneumonia combined were the seventh leading causes of death in the United States, ${ }^{3,4}$ down from sixth in previous years, and represented an age-adjusted death rate of 21.8 per 100,000 patients. ${ }^{3}$ Death rates from CAP increase with the presence of comorbidity and increased age; the condition affects persons of any race or sex equally. The decrease in death rates from pneumonia and influenza are largely attributed to vaccines for vulnerable populations (e.g., older and immunocompromised persons).

\section{Clinical Presentation}

Pneumonia is an inflammation or infection of the lungs that causes them to function abnormally. Pneumonia can be classified as typical or atypical, although the clinical presentations are often similar. Several symptoms commonly present in patients with pneumonia.

\section{TYPES OF CAP}

Typical pneumonia usually is caused by bacteria such as Streptococcus pneumoniae. Atypical pneumonia usually is caused by the influenza virus, mycoplasma, chlamydia, legionella, adenovirus, or other unidentified microorganism. The patient's age is the main differentiating factor between typical and atypical pneumonia; young adults are more prone to atypical causes, ${ }^{5,6}$ and very 
SORT: KEY RECOMMENDATIONS FOR PRACTICE

\begin{tabular}{llc} 
Clinical recommendation & $\begin{array}{l}\text { Evidence } \\
\text { rating }\end{array}$ & References \\
\hline $\begin{array}{l}\text { Patients with suspected community-acquired pneumonia (CAP) should } \\
\text { receive chest radiography. }\end{array}$ & $\mathrm{C}$ & 8 \\
$\begin{array}{l}\text { The Pneumonia Severity Index should be used to assist in decisions } \\
\text { regarding hospitalization of patients with CAP. }\end{array}$ & $\mathrm{A}$ & $8,9,15,16$ \\
$\begin{array}{l}\text { The initial treatment of CAP is empiric, and macrolides or doxycycline } \\
\text { (Vibramycin) should be used in most patients. }\end{array}$ & $\mathrm{C}$ & $8,9,29$ \\
$\begin{array}{l}\text { Respiratory fluoroquinolones should be used when patients have failed } \\
\text { first-line regimens, have significant comorbidities, have } \\
\text { had recent antibiotic therapy, are allergic to alternative agents, or have } \\
\text { a documented infection with highly drug-resistant pneumococci. }\end{array}$ & $\mathrm{C}$ & $8,9,28,29$ \\
\hline
\end{tabular}

$A=$ consistent, good-quality patient-oriented evidence; $B=$ inconsistent or limited-quality patient-oriented evidence; $C$ = consensus, disease-oriented evidence, usual practice, expert opinion, or case series. For information about the SORT evidence rating system, see page 374 or http://WwW.aafp.org/afpsort.xml.

young and older persons are more predisposed to typical causes.

\section{SYMPTOMS}

Common clinical symptoms of CAP include cough, fever, chills, fatigue, dyspnea, rigors, and pleuritic chest pain. Depending on the pathogen, a patient's cough may be persistent and dry, or it may produce sputum. Other pre- sentations may include headache and myalgia. Certain etiologies, such as legionella, also may produce gastrointestinal symptoms.

\section{Diagnosis PHYSICAL EXAMINATION}

Physical examination may reveal dullness to percussion of the chest, crackles or rales on auscultation, bronchial breath sounds,

TABLE 1

Overview of Community-Acquired Pneumonia

\section{Definition}

Lower respiratory tract infection in a nonhospitalized person that is associated with symptoms of acute infection with or without new infiltrate on chest radiographs

\section{Clinical presentation}

Temperature greater than $38^{\circ} \mathrm{C}\left(100.4^{\circ} \mathrm{F}\right)$

Cough with or without sputum, hemoptysis

Pleuritic chest pain

Myalgia

Gastrointestinal symptoms

Dyspnea

Malaise, fatigue

Rales, rhonchi, wheezing

Egophony, bronchial breath sounds

Dullness to percussion

Atypical symptoms in older patients

\section{Etiology}

Bacterial

Chlamydia species

Haemophilus influenzae

Legionella species

Moraxella catarrhalis

Mycoplasma pneumoniae

Staphylococcus aureus

Streptococcus pneumoniae

Viral

\section{Adenovirus}

Influenza A and B

Parainfluenza

Respiratory syncytial virus

Endemic fungi

Blastomycosis

Coccidioidomycosis

Histoplasmosis

\section{Risk factors}

Age older than 65 years

Human immunodeficiency virus or immunocompromised

Recent antibiotic therapy or resistance to antibiotics

Comorbidities

Asthma

Cerebrovascular disease

Chronic obstructive pulmonary disease

Chronic renal failure

Congestive heart failure

Diabetes

Liver disease

Neoplastic disease 
tactile fremitus, and egophony ("E" to "A" changes). The patient also may be tachypneic. A prospective study ${ }^{7}$ showed that patients with typical pneumonia were more likely than not to present with dyspnea and bronchial breath sounds on auscultation.

\section{RADIOGRAPHY}

Chest radiography (posteroanterior and lateral views) has been shown to be a critical component in diagnosing pneumonia. ${ }^{8}$ According to

TABLE 2

\section{Sensitivity and Specificity of Diagnostic Tests for CAP}

\begin{tabular}{|c|c|c|}
\hline Diagnostic tests by pathogen & Sensitivity (\%) & Specificity (\%) \\
\hline \multicolumn{3}{|l|}{ Chlamydia } \\
\hline Rapid PCR (sputum, BAL fluid) & 30 to 95 & $>95$ \\
\hline $\begin{array}{l}\text { Serology (fourfold rise in serum } \\
\text { and convalescent titers) }\end{array}$ & 10 to 100 & - \\
\hline Sputum culture & 10 to 80 & $>95$ \\
\hline \multicolumn{3}{|l|}{ Gram-negative rods } \\
\hline Sputum Gram stain & 15 to 100 & 11 to 100 \\
\hline \multicolumn{3}{|l|}{$\begin{array}{l}\text { Haemophilus influenzae, } \\
\text { Moraxella catarrhalis, } \\
\text { Pneumoniae }\end{array}$} \\
\hline Sputum culture & $\begin{array}{l}\text { Diagnostic yield } \\
20 \text { to } 79 *\end{array}$ & $\begin{array}{l}\text { Diagnostic yield } \\
20 \text { to } 79 *\end{array}$ \\
\hline \multicolumn{3}{|l|}{ Influenza } \\
\hline Rapid DFA (sputum, BAL fluid) & 22 to 75 & 90 \\
\hline \multicolumn{3}{|l|}{ Legionella pneumophila } \\
\hline DFA (sputum, BAL fluid) & 22 to 75 & 90 \\
\hline PCR (sputum, BAL fluid) & 83 to 100 & $>95$ \\
\hline Serum acute titer & 10 to 27 & $>85$ \\
\hline Urinary antigen & 55 to 90 & $>95$ \\
\hline \multicolumn{3}{|l|}{ Mycoplasma pneumoniae } \\
\hline Antibiotic titers & 75 to 95 & $>90$ \\
\hline Cold agglutinins & 50 to 60 & - \\
\hline PCR (sputum, BAL fluid) & 30 to 95 & $>95$ \\
\hline \multicolumn{3}{|l|}{ Pneumococcal pneumoniae } \\
\hline Chest radiography (lobar infiltrate) & $40 \dagger$ & - \\
\hline Sputum culture & $\begin{array}{l}\text { Diagnostic yield } \\
20 \text { to } 79 *\end{array}$ & $\begin{array}{l}\text { Diagnostic yield } \\
20 \text { to } 79 *\end{array}$ \\
\hline Sputum Gram stain & 15 to 100 & 11 to 100 \\
\hline
\end{tabular}

$C A P=$ community-acquired pneumonia; $P C R=$ polymerase chain reaction; $B A L=$ bronchoalveolar lavage; DFA = direct fluorescence antibody.

*-Overgrowth of oral flora, isolation of atypical agents requires special media. $\dagger$-Acute symptoms.

Information from references 2, 8, 11, and 13 . the latest American Thoracic Society (ATS) guidelines for the diagnosis and treatment of adults with CAP, "all patients with suspected CAP should have a chest radiograph to establish the diagnosis and identify complications (pleural effusion, multilobar disease)." ${ }^{8}$ Chest radiography may reveal a lobar consolidation, which is common in typical pneumonia; or it could show bilateral, more diffuse infiltrates than those commonly seen in atypical pneumonia. However, chest radiography performed early in the course of the disease could be negative.

\section{LABORATORY TESTS}

Historically, common laboratory tests for pneumonia have included leukocyte count, sputum Gram stain, two sets of blood cultures, and urine antigens. However, the validity of these tests has recently been questioned after low positive culture rates were found (e.g., culture isolates of S. pneumoniae were present in only 40 to 50 percent of cases). ${ }^{9}$ Such low positive culture rates are likely due to problems with retrieving samples from the lower respiratory tract, previous administration of antibiotics, contamination from the upper airways, faulty separation of sputum from saliva when streaking slides or plates, ${ }^{9}$ or viral etiology. Furthermore, sputum samples are adequate in only 52.3 percent of patients with CAP, and only 44 percent of those samples contain pathogens. ${ }^{10}$ Nonetheless, initial therapy often is guided by the assumption that the presenting disease is caused by a common bacterial pathogen.

Findings ${ }^{11}$ also cast doubt on the clinical utility of obtaining blood cultures from patients with suspected CAP. In a study ${ }^{12}$ of CAP cases in 19 Canadian hospitals over a six-month period, positive blood cultures were obtained in only 5.2 to 6.2 percent of patients, including those with the most severe disease. Based on these findings, other researchers ${ }^{13}$ concluded that a positive blood culture had no correlation with the severity of the illness or outcome. Another prospective study ${ }^{10}$ showed that blood cultures were positive in only 10.5 percent of patients with pneumonia. Despite these and 
other research findings, current ATS guidelines ${ }^{8}$ recommend that patients hospitalized for suspected CAP receive two sets of blood cultures. Blood cultures, however, are not necessary for outpatient diagnosis. ${ }^{8}$

Legionella antigens were found in the urine of 48 percent of patients with suspected Legionella pneumophila serogroup 1 infection. ${ }^{14}$ Table $2^{2,8,11,13}$ includes the sensitivity and specificity of diagnostic tests for CAP.

\section{Treatment}

Initial treatment of CAP is based on physical examination findings, laboratory results, and patient characteristics (e.g., age, chronic illnesses, history of smoking, history of the illness). ${ }^{15}$ Physicians should begin their treatment decisions by assessing the need for hospitalization using a prediction tool for increased mortality, such as the Pneumonia Severity Index (Table $3^{15}$ ), combined with clinical judgment. ${ }^{9}$

\section{OUTPATIENT VS. INPATIENT TREATMENT}

Choosing between outpatient and inpatient treatment is a crucial decision because of the possible risk of death., ${ }^{9,15,16}$ This decision not only influences diagnostic testing and medication choices, it can have a psychological impact on patients and their families. On average, the estimated cost for inpatient care of patients with CAP is $\$ 7,500$. Outpatient care can cost as little as $\$ 150$ to $\$ 350 .^{17-19}$ Hospitalization of a patient should depend on patient age, comorbidities, and the severity of the presenting disease. ${ }^{9,20}$

Physicians tend to overestimate a patient's risk of death ${ }^{14}$; therefore, many low-risk patients who could be safely treated as outpatients are admitted for more costly inpatient care. The Pneumonia Severity Index (Table $3^{15}$ ) was developed to assist physicians in identifying patients at a higher risk of complications and who are more likely to benefit from hospitalization., ${ }^{9}, 15,16$ Investigators developed a risk model based on a prospective cohort study ${ }^{16}$ of 2,287 patients with CAP in Pittsburgh, Boston, and Halifax, Nova Scotia. By using the model, the authors found that 26 to 31 percent of the hospitalized patients were good outpatient candidates, and an additional 13 to 19 percent only needed brief hospital observation. They validated this model using data ${ }^{17}$ from more than 50,000 patients with CAP in 275 U.S. and Canadian hospitals. ${ }^{15-17,21,22}$

\section{TABLE 3}

\section{Pneumonia Severity Index}

\begin{tabular}{|c|c|c|c|c|}
\hline \multicolumn{4}{|c|}{ Patient Characteristics } & Points \\
\hline \multicolumn{5}{|l|}{ Demographics } \\
\hline \multicolumn{4}{|l|}{ Male } & Age (years) \\
\hline \multicolumn{4}{|l|}{ Female } & Age (years) - 10 \\
\hline \multicolumn{4}{|c|}{ Nursing home resident } & +10 \\
\hline \multicolumn{5}{|c|}{ Comorbid illness } \\
\hline \multicolumn{4}{|c|}{ Neoplastic disease } & +30 \\
\hline \multicolumn{4}{|l|}{ Liver disease } & +20 \\
\hline \multicolumn{4}{|c|}{ Congestive heart failure } & +10 \\
\hline \multicolumn{4}{|c|}{ Cerebrovascular disease } & +10 \\
\hline \multicolumn{4}{|l|}{ Renal disease } & +10 \\
\hline \multicolumn{5}{|c|}{ Physical examination findings } \\
\hline \multicolumn{4}{|c|}{ Altered mental status } & +20 \\
\hline \multicolumn{4}{|c|}{ Respiratory rate $>30$ breaths per minute } & +20 \\
\hline \multicolumn{4}{|c|}{ Systolic blood pressure $<90 \mathrm{~mm} \mathrm{Hg}$} & +20 \\
\hline \multicolumn{4}{|c|}{ Temperature $<35^{\circ} \mathrm{C}\left(95^{\circ} \mathrm{F}\right)$ or $>40^{\circ} \mathrm{C}\left(104^{\circ} \mathrm{F}\right)$} & +15 \\
\hline \multicolumn{4}{|c|}{ Pulse rate $>125$ beats per minute } & +10 \\
\hline \multicolumn{5}{|c|}{ Laboratory and radiographic findings } \\
\hline \multicolumn{4}{|c|}{ Arterial $\mathrm{pH}<7.35$} & +30 \\
\hline \multicolumn{4}{|c|}{$\begin{array}{l}\text { Blood urea nitrogen }>64 \mathrm{mg} \text { per } \mathrm{dL} \\
(22.85 \mathrm{mmol} \text { per } \mathrm{L})\end{array}$} & +20 \\
\hline \multicolumn{4}{|c|}{ Sodium < 130 mEq per L (130 mmol per L) } & +20 \\
\hline \multicolumn{4}{|c|}{ Glucose $>250$ mg per dL (13.87 mmol per L) } & +10 \\
\hline \multicolumn{4}{|c|}{ Hematocrit $<30$ percent } & +10 \\
\hline \multicolumn{4}{|c|}{$\begin{array}{l}\text { Partial pressure of arterial oxygen }<60 \mathrm{~mm} \mathrm{Hg} \text { or } \\
\text { oxygen percent saturation }<90 \text { percent }\end{array}$} & +10 \\
\hline \multicolumn{4}{|l|}{ Pleural effusion } & +10 \\
\hline & & & Total points: & \\
\hline Point total & Risk & $\begin{array}{l}\text { Risk } \\
\text { class }\end{array}$ & $\begin{array}{l}\text { Mortality \% } \\
\text { (No. of patients) }\end{array}$ & $\begin{array}{l}\text { Recommended } \\
\text { site of care }\end{array}$ \\
\hline No predictors & Low & I & $0.1(3,034)$ & Outpatient \\
\hline$\leq 70$ & Low & $\|$ & $0.6(5,778)$ & Outpatient \\
\hline 71 to 90 & Low & III & $2.8(6,790)$ & $\begin{array}{l}\text { Inpatient } \\
\text { (briefly) }\end{array}$ \\
\hline 91 to 130 & Moderate & IV & $8.2(13,104)$ & Inpatient \\
\hline$>130$ & High & V & $29.2(9,333)$ & Inpatient \\
\hline
\end{tabular}

Information from reference 15. 
Although the Pneumonia Severity Index can serve as a general guideline for management, clinical judgment should always supersede the prognostic score. ${ }^{9}$

\section{PHARMACOTHERAPY}

The primary goals of pharmacotherapy for patients with CAP include eradicating the causative pathogens, resolving the clinical signs and symptoms, minimizing hospitalization, and preventing reinfection. ${ }^{23-27}$ Physicians should choose a medication based on the pharmacokinetic profile, adverse reactions, drug interactions, and cost-effectiveness. ${ }^{23-27}$ Further, patient evaluation should focus on severity of illness, patient age, comorbidities, clinical presentation, epidemiologic setting, and previous exposure. ${ }^{9}$ The majority of patients with CAP are treated empirically based on the most common pathogen(s) associated with the condition. ${ }^{23-27}$

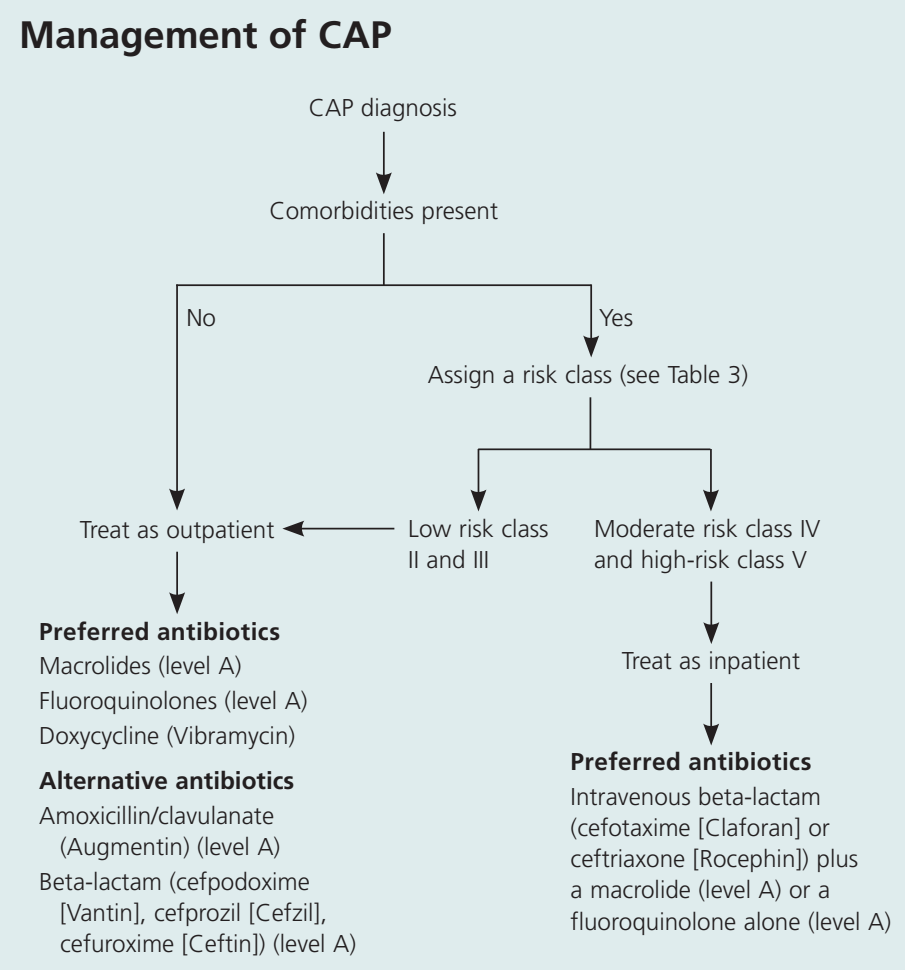

Figure 1. Algorithm for the management of CAP. (CAP = communityacquired pneumonia.)

Adapted with permission from Fish D. Pneumonia. PSAP, Pharmacotherapy Self-Assessment Program. Kansas City, Mo.: American College of Clinical Pharmacy, 2002:202.
Consensus guidelines from ATS, ${ }^{8}$ Infectious Diseases Society of America, ${ }^{9}$ and Canadian Guidelines for the Initial Management of Community-Acquired Pneumonia ${ }^{28}$ (Figure $\left.1^{6}\right)$ recommend initial empiric therapy with macrolides, fluoroquinolones, or doxycycline (Vibramycin). A fourth guideline $^{29}$ developed by the Therapeutic Working Group of the CDC, however, recommends using fluoroquinolones sparingly because of resistance concerns.

Although data are limited on duration of CAP therapy, current research ${ }^{30}$ recommends seven to 10 days of therapy for S. pneumoniae and 10 to 14 days of therapy for Mycoplasma pneumoniae and Chlamydia pneumoniae. After a hospitalized patient is clinically stable (i.e., temperature less than $37.8^{\circ} \mathrm{C}\left[100.0^{\circ} \mathrm{F}\right]$, pulse under 100 beats per minute, respiratory rate below 24 breaths per minute, systolic blood pressure above $90 \mathrm{~mm} \mathrm{Hg}$, and blood oxygen saturation over 90 percent) and able to tolerate oral intake, the patient may be treated with oral antibiotics for the remainder of the therapy course. This can save money and allow for earlier hospital discharge, which minimizes a patient's risk of hospital-acquired infection.

\section{Pneumococcal Resistance}

S. pneumoniae, which accounts for 60 to 70 percent of all bacterial CAP cases, can affect all patient groups and can cause a fatal form of CAP. The alarming rate of resistance to many commonly used antibiotics raises great concern. Penicillin-resistant S. pneumoniae was uncommon in the early 1990s but has since become increasingly prevalent. ${ }^{29,31}$

Resistant strains are classified as having intermediate or high-level resistance. Surveillance data in the United States ${ }^{30}$ revealed that, overall, pneumococcal strains had a 28 percent immediate resistance rate and a 16 percent high-level resistance rate. Decreased susceptibility to other commonly used antibiotics has also been observed (Table 42). ${ }^{39-31}$ The clinical importance of these data is questionable because recruiting patients infected with resistant pathogens for clinical trials is difficult. Furthermore, available outcomes on the treatment of 
TABLE 4

Patterns of Resistance to Antibiotics in North America*

\begin{tabular}{|c|c|}
\hline Antibiotic & $\begin{array}{l}\text { Resistance } \\
(\%) \dagger\end{array}$ \\
\hline \multicolumn{2}{|l|}{ Penicillins } \\
\hline $\begin{array}{l}\text { Amoxicillin/clavulanate } \\
\text { (Augmentin) }\end{array}$ & 4.1 \\
\hline Penicillin & 21.3 \\
\hline \multicolumn{2}{|l|}{ Cephalosporins } \\
\hline Cefepime (Maxipime) & 0.4 \\
\hline Cefprozil (Cefzil) & 23.9 \\
\hline Ceftriaxone (Rocephin) & 1.9 \\
\hline Cefuroxime (Ceftin) & 24.7 \\
\hline \multicolumn{2}{|l|}{ Macrolides } \\
\hline Azithromycin (Zithromax) & 23.0 \\
\hline Clarithromycin (Biaxin) & 26.6 \\
\hline Erythromycin & 28.3 \\
\hline \multicolumn{2}{|l|}{ Fluoroquinolones } \\
\hline Gatifloxacin (Tequin) & 0.7 \\
\hline Levofloxacin (Levaquin) & 0.7 \\
\hline Moxifloxacin (Avelox) & 0.4 \\
\hline \multicolumn{2}{|l|}{ Miscellaneous } \\
\hline Clindamycin (Cleocin) & 9.2 \\
\hline Tetracycline & 18.8 \\
\hline $\begin{array}{l}\text { Trimethoprim/sulfamethoxazole } \\
\text { (Bactrim, Septra) }\end{array}$ & 29.9 \\
\hline Vancomycin (Vancocin) & 0.0 \\
\hline \multicolumn{2}{|c|}{$\begin{array}{l}\text { *-Antibiotics tested against Streptococcus pneu- } \\
\text { moniae isolates. } \\
\dagger-\text { Resistance rates averaged across all patient age } \\
\text { groups. } \\
\text { Information from reference } 32 \text {. }\end{array}$} \\
\hline
\end{tabular}

pneumonia caused by resistant pneumococcal strains are conflicting. ${ }^{30}$

The CDC and others recommend outpatient oral empirical antibiotics with a macrolide, doxycycline, or an oral beta-lactam (amoxicillin, cefuroxime [Ceftin], or amoxicillin/clavulanate [Augmentin]) or inpatient treatment with an intravenous beta-lactam (cefuroxime, ceftriaxone [Rocephin], cefotaxime [Claforan]) or a combination of ampicillin/sulbactam (Unasyn) with a macrolide (Figure $1^{6}$ ). ${ }^{28,29}$ Conservative use of new fluoroquinolones (levofloxacin [Levaquin], gatifloxacin [Tequin], moxifloxacin [Avelox]) also is recommended to minimize resistance patterns. ${ }^{28,29}$ The new fluoroquinolones (minimum inhibitory concentration: $4 \mathrm{mcg}$ per $\mathrm{mL}$ or greater) should be used only when patients have failed recommended first-line regimens, are allergic to alternative agents, or have a documented infection with highly drug-resistant pneumococci such as those resistant to penicillin. ${ }^{28,29}$

\section{Cost of Antimicrobial Therapy}

Economic pressures have accentuated the focus on reducing health care costs and utilizing resources while maintaining or improving quality of care. ${ }^{31}$ These pressures are exacerbated by the growing resistance of $S$. pneumoniae to penicillin..$^{31,32}$ This pattern of resistance increases the cost of treatment because of prolonged hospitalization, relapses, and the use of more expensive antibacterial agents. ${ }^{33-37}$

\section{REDUCING COSTS}

Numerous methods for reducing costs when treating patients with bacterial infections can be applied to CAP (Table 5). Choosing monotherapy instead of combination therapy

TABLE 5

Strategies for Reducing the Cost of Antibiotic Therapy

\section{Administration}

Use the shortest appropriate course possible. Switch from parenteral to oral antibiotics as soon as clinically appropriate.

\section{Adverse events}

Avoid agents with serious or costly adverse effects.

Avoid agents known to induce resistance.

\section{Drug cost}

Compare low impact with total hospital costs (but significant to pharmacy costs).

\section{Hospitalization}

Use knowledge of local resistance to initiate early therapy with appropriate spectrum agent (few data available).

Consider availability and cost-effectiveness of intravenous versus oral administration.

\section{Monitoring}

Avoid agents that require therapeutic monitoring or laboratory safety tests.

\section{Pharmacotherapy}

Use long-acting antibiotics.

Use potent bactericides.

Avoid antibiotics with poor tissue penetration. 
TABLE 6

\section{Antimicrobial Therapies for CAP}

\begin{tabular}{|c|c|c|c|}
\hline Agent & Dosage* & Cost per course $\dagger$ (generic) & Common adverse reactions $\ddagger$ \\
\hline \multicolumn{3}{|l|}{ Cephalosporins } & \multirow{7}{*}{$\begin{array}{l}\text { Mild diarrhea } \\
\text { Rash }\end{array}$} \\
\hline Cefotaxime (Claforan) & $1 \mathrm{~g}$ IV every six to eight hours & $\$ 355(330)$ & \\
\hline Cefpodoxime (Vantin) & 200 mg orally twice per day & $124(110)$ & \\
\hline Cefprozil (Cefzil) & 500 mg orally twice per day & 192 & \\
\hline Ceftriaxone (Rocephin) & $1 \mathrm{~g}$ IV every 24 hours & 392 & \\
\hline \multirow[t]{2}{*}{ Cefuroxime (Ceftin) } & 500 mg orally twice per day & 219 oral & \\
\hline & 0.75 to $1.5 \mathrm{~g}$ IV every eight hours & 250 to 358 IV & \\
\hline Clindamycins & & & Mild diarrhea \\
\hline \multirow[t]{3}{*}{ Clindamycin (Cleocin) } & 300 mg orally every six hours & 238 (148 to 168$)$ oral & Abdominal pain \\
\hline & 600 mg IV every eight hours & $250 \mathrm{IV}$ & Pseudomembranous colitis \\
\hline & & & Rash \\
\hline Fluoroquinolones & & & Mild diarrhea \\
\hline Gatifloxacin (Tequin) & 400 mg orally or IV once per day & 98 oral, 382 IV & Nausea \\
\hline Levofloxacin (Levaquin) & 500 mg orally or IV once per day & 56 oral, 438 IV & Vomiting \\
\hline \multirow[t]{3}{*}{ Moxifloxacin (Avelox) } & 400 mg orally once per day & 107 & Constipation \\
\hline & & & Dizziness \\
\hline & & & Headache \\
\hline Macrolides & & & Mild diarrhea \\
\hline \multirow[t]{3}{*}{ Azithromycin (Zithromax) } & 500 mg orally for one dose, then & 49 to 60 oral & Nausea \\
\hline & 250 mg once per day for four doses & & Vomiting \\
\hline & 500 mg IV every 24 hours & 295 IV & Abdominal pain \\
\hline Clarithromycin (Biaxin) & 500 mg orally twice per day & 96 & Rash \\
\hline Erythromycin & $\begin{array}{l}500 \text { mg orally every six hours } \\
500 \text { to } 1,000 \mathrm{mg} \text { IV every six hours }\end{array}$ & $\begin{array}{l}17 \text { (8 to } 10) \text { oral } \\
\text { (167) IV }\end{array}$ & \\
\hline
\end{tabular}

\begin{tabular}{|c|c|c|c|}
\hline Penicillins & & & Mild diarrhea \\
\hline \multirow[t]{2}{*}{ Amoxicillin } & 500 mg orally every eight hours & 4 (4 to 8$)$ & Nausea \\
\hline & 875 mg orally every 12 hours & $20(18$ to 19$)$ & Vomiting \\
\hline $\begin{array}{l}\text { Amoxicillin/clavulanate } \\
\text { (Augmentin) }\end{array}$ & 875 mg/125mg orally every 12 hours & $166(110$ to 115$)$ & Rash \\
\hline Penicillin G & 1 to $3 \mathrm{mU}$ IV every four hours & $(273)$ & \\
\hline Penicillin V & 500 mg orally four times per day & 15 (9 to 15$)$ & \\
\hline Tetracyclines & & & Mild diarrhea \\
\hline \multirow[t]{3}{*}{ Doxycycline (Vibramycin) } & 100 mg orally twice per day & 102 (16 to 21$)$ & Nausea \\
\hline & & & Vomiting \\
\hline & & & Phototoxicity \\
\hline
\end{tabular}

$C A P=$ community-acquired pneumonia; $I V=$ intravenously.

*_Usual duration for adults with CAP and normal renal function is 10 to 14 days.

†-Estimated cost to the pharmacist based on average wholesale prices in Red Book. Montvale, N.J.: Medical Economics Data, 2005. Cost to the patient will be higher, depending on prescription filling fee.

\$-Adverse events occurring at a rate of approximately 1 to 10 percent.

Adapted with permission from Fish D. Pneumonia. Pharmacotherapy Self-Assessment Program. 4th ed. Kansas City, Mo.: American College of Clinical Pharmacy 2002:198.

reduces costs associated with administering an antibacterial. ${ }^{33-37}$ Using agents with longer half-lives allows for once-daily administration, which in turn leads to improved compliance and outcomes and decreased costs. ${ }^{33-37}$ In addition, transitioning patients to oral therapy as soon as they are clinically stable can significantly reduce the length of hospitalization-the major contributing factor to health care costs. ${ }^{33-37}$ 


\section{COST-EFFECTIVE CARE}

When choosing a treatment, it is essential to compare costs and outcomes of all recommended drug therapies. ${ }^{31}$ Table $6^{6}$ includes the costs of and common adverse reactions to antimicrobial therapies for CAP.

The goal of a formal pharmacoeconomic assessment is to enhance overall patient care using available resources. The evaluation should lead to a decision that will maximize the value of health care services, not simply reduce the costs of drug therapy. For instance, a particular drug may be more expensive, but it may also be more effective, thus lowering overall costs. Another drug may have a higher rate of treatment failures, creating added costs associated with managing the failures. The overall cost of each therapy should be obtained by comparing the end cost with the probability of achieving a positive outcome. Depending on the relative costs associated with treatment failures compared with the costs of cures, the decision to choose one agent over another may change.

The best way to apply cost-saving approaches to the treatment of patients with CAP is by using a clinical pathway. ${ }^{38}$ This is a method of facilitating multidisciplinary patient care by moving processes of care sequentially through various stages, within specified time frames, toward a desired outcome. These pathways should be specific to each institution, taking into account resistance rates in the community and encouraging the use of the most active, cost-effective agents to produce rapid, positive clinical outcomes. ${ }^{31,39}$

The authors thank Joel Emery McCullough, M.D., M.S., M.P.H., and Adam Reyburn, M.D., for their assistance in the preparation of the manuscript.

\section{The Authors}

M. NAWAL LUTFIYYA, PH.D., is assistant professor and director of research in the Department of Family and Community Medicine at the University of Illinois College of Medicine at Rockford. She also is adjunct assistant professor in the University of Illinois at Chicago (UIC) School of Public Health. Dr. Lutfiyya earned her doctorate at the University of Massachusetts at Amherst after completing other graduatelevel training at the University of lowa, lowa City.

ERIC HENLEY, M.D., M.P.H., is associate professor and head of the Department of Family and Community Medicine at the University of Illinois College of Medicine at Rockford.
He is an adjunct faculty member in the UIC School of Public Health. Dr. Henley received his medical degree from Georgetown University, Washington, D.C., and completed a family medicine residency at the University of Connecticut School of Medicine, Hartford. He earned his master's in public health at Harvard Medical School, Boston, Mass.

LINDA F. CHANG, PHARM.D., M.P.H., B.C.P.S., is clinical assistant professor in the Department of Family and Community Medicine and the Department of Pharmacy Practice at the University of Illinois College of Medicine at Rockford. She received a doctorate in pharmacy at UIC and completed a general practice pharmacy residency at the Chicago Veterans Administration Hospital.

STEPHANIE WESSEL REYBURN, M.D., M.P.H., is a family practice resident at the Mayo School of Graduate Medical Education, Rochester, Minn. She received her medical degree at the University of Illinois College of Medicine at Rockford and her master's at the UIC School of Public Health.

Address correspondence to M. Nawal Lutfiyya, Ph.D., University of Illinois College of Medicine at Rockford, Department of Family and Community Medicine, 1601 Parkview Ave., Rockford, IL 61107 (email: lutfiyya@uic. edu). Reprints are not available from the authors.

Author disclosure: Nothing to disclose.

\section{REFERENCES}

1. Andrews J, Nadjm B, Gant V, Shetty N. Communityacquired pneumonia. Curr Opin Pulm Med 2003;9: 175-80.

2. Niederman MS. Community-acquired pneumonia: management controversies, part 1; practical recommendations from the latest guidelines. J Respir Dis 2002; 23:10-7.

3. Arias E, Anderson RN, Kung HC, Murphy SL, Kochanek KD. Deaths: final data for 2001. Natl Vital Stat Rep 2003; 52:1-115

4. Hall MJ, DeFrances CJ. 2001 National hospital discharge survey. Adv Data 2004:1-20.

5. File TM. Community-acquired pneumonia. Lancet 2003;362:1991-2001.

6. Fish D. Pneumonia. In: Pharmacotherapy self-assessment program. 4th ed. Kansas City: American College of Clinical Pharmacy, 2002.

7. Beovic B, Bonac B, Kese D, Avsic-Zupanc T, Kreft S, Lesnicar G, et al. Aetiology and clinical presentation of mild community-acquired bacterial pneumonia. Eur J Clin Microbiol Infect Dis 2003;22:584-91.

8. Niederman MS, Mandell LA, Anzueto A, Bass JB, Broughton WA, Campbell GD, et al. American Thoracic Society. Guidelines for the management of adults with community-acquired pneumonia. Diagnosis, assessment of severity, antimicrobial therapy, and prevention. Am J Respir Crit Care Med 2001;163:1730-54.

9. Mandell LA, Bartlett JG, Dowell SF, File TM Jr, Musher DM, Whitney C. Infectious Diseases Society of America. Update of practice guidelines for the management of community-acquired pneumonia in immunocompetent adults. Clin Infect Dis 2003;37:1405-33.

10. Sopena N, Sabria M, Pedro-Botet ML, Manterola JM, Matas L, Dominguez J, et al. Prospective study of 


\section{Community-Acquired Pneumonia}

community-acquired pneumonia of bacterial etiology in adults. Eur J Clin Microbiol Infect Dis 1999;18:852-8.

11. Campbell SG, Marrie TJ, Anstey R, Dickinson G, Ackroyd-Stolarz $S$. The contribution of blood cultures to the clinical management of adult patients admitted to the hospital with community-acquired pneumonia: a prospective observational study. Chest 2003;123:1142-50.

12. Feagan BG. A controlled trial of a critical pathway for treating community-acquired pneumonia: the CAPITAL study. Community-Acquired Pneumonia Intervention Trial Assessing Levofloxacin. Pharmacotherapy 2001;21(pt 2):S89-94.

13. Priebe DL, Chambliss ML. Blood cultures not helpful for community-acquired pneumonia. J Fam Pract 2003;52:599-600.

14. Sopena N, Sabria-Leal M, Pedro-Botet ML, Padilla E, Dominguez J, Morera J, et al. Comparative study of the clinical presentation of Legionella pneumonia and other community-acquired pneumonias. Chest 1998; 113:1195-200.

15. Fine MJ, Auble TE, Yealy DM, Hanusa BH, Weissfeld LA, Singer $D E$, et al. A prediction rule to identify low-risk patients with community-acquired pneumonia. N Engl J Med 1997;336:243-50.

16. Fine MJ, Hough LJ, Medsger AR, Li YH, Ricci EM, Singer $D E$, et al. The hospital admission decision for patients with community-acquired pneumonia. Results from the Pneumonia Patient Outcomes Research Team cohort study. Arch Intern Med 1997;157:36-44.

17. Fine MJ, Pratt HM, Obrosky DS, Lave JR, Mclntosh LJ, Singer DE, et al. Relation between length of hospital stay and costs of care for patients with communityacquired pneumonia. Am J Med 2000;109:378-85.

18. Goss CH, Rubenfeld GD, Park DR, Sherbin VL, Goodman MS, Root RK. Cost and incidence of social comorbidities in low-risk patients with communityacquired pneumonia admitted to a public hospital. Chest 2003;124:2148-55.

19. Hoe LK, Keang LT. Hospitalized low-risk communityacquired pneumonia: outcome and potential for costsavings. Respirology 1999;4:307-9.

20. Ruiz M, Ewig S, Marcos MA, Martinez JA, Arancibia F, Mensa J, et al. Etiology of community-acquired pneumonia: impact of age, comorbidity, and severity. Am J Respir Crit Care Med 1999;160:397-405.

21. Arnold FW, Ramirez JA, McDonald LC, Xia EL. Hospitalization for community-acquired pneumonia: the pneumonia severity index vs clinical judgment. Chest 2003; 124:121-4.

22. Roson B, Carratala J, Dorca J, Casanova A, Manresa F, Gudiol F. Etiology, reasons for hospitalization, risk classes, and outcomes of community-acquired pneumonia in patients hospitalized on the basis of conventional admission criteria. Clin Infect Dis 2001;33:158-65.

23. Mandell LA. Community-acquired pneumonia. Etiology, epidemiology, and treatment. Chest 1995;108(suppl): S35-42.

24. Mandell LA. Antibiotic therapy for community-acquired pneumonia. Clin Chest Med 1999;20:589-98.

25. Mandell LA. Antimicrobial approaches to therapy for pneumonia. Curr Opin Pulm Med 1996;2:218-27.
26. Mundy LM, Oldach D, Auwaerter PG, Gaydos CA, Moore RD, Bartlett JG, et al., for the Hopkins CAP team. Implications for macrolide treatment in community-acquired pneumonia. Chest 1998;113:1201-6.

27. Mandell LA. Antibiotics for pneumonia therapy. Med Clin North Am 1994;78:997-1014.

28. Mandell LA, Marrie TJ, Grossman RF, Chow AW, Hyland $\mathrm{RH}$, for the Canadian Community-Acquired Pneumonia Working Group. Canadian guidelines for the initial management of community-acquired pneumonia: an evidence-based update by the Canadian Infectious Diseases Society and the Canadian Thoracic Society. Clin Infect Dis 2000;31:383-421.

29. Heffelfinger JD, Dowell SF, Jorgensen JH, Klugman KP, Mabry LR, Musher DM, et al. Management of community-acquired pneumonia in the era of pneumococcal resistance: a report from the Drug-Resistant Streptococcus pneumoniae Working Group. Arch Intern Med 2000;160:1399-408.

30. Mandell LA, Bergeron MC, Gribble MJ, et al. Sequential antibiotic therapy: effective cost management and patient care. Can J Infect Dis 1995;6:306.

31. Kuti JL, CapitanoB, Nicolau DP. Cost-effectiveapproaches to the treatment of community-acquired pneumonia in the era of resistance. Pharmacoeconomics 2002;20: 513-28.

32. Jones RN, Biedenbach DJ, Beach ML. Influence of patient age on the susceptibility patterns of Streptococcus pneumoniae isolates in North America (2000-2001): report from the SENTRY Antimicrobial Surveillance Program. Diagn Microbiol Infect Dis 2003;46:77-80.

33. Begg EJ, Barclay ML, Kirkpatrick CM. The therapeutic monitoring of antimicrobial agents. Br J Clin Pharmacol 2001;52(suppl 1):S35-43.

34. Milkovich G. Intravenous-to-oral transition therapy in community-acquired pneumonia: the INOVA Health System experience. Pharmacotherapy 2001;21 (pt 2):S83-8.

35. Weingarten SR, Riedinger MS, Varis G, Noah MS, Belman MJ, Meyer RD, et al. Identification of low-risk hospitalized patients with pneumonia. Implications for early conversion to oral antimicrobial therapy. Chest 1994;105:1109-15.

36. Siegel RE, Halpern NA, Almenoff PL, Lee A, Cashin R, Greene JG. A prospective randomized study of in-patient iv. antibiotics for community-acquired pneumonia. The optimal duration of therapy. Chest 1996;110:965-71.

37. Ramirez JA, Vargas S, Ritter GW, Brier ME, Wright A, Smith $S$, et al. Early switch from intravenous to oral antibiotics and early hospital discharge: a prospective observational study of 200 consecutive patients with community-acquired pneumonia. Arch Intern Med 1999;159:2449-54.

38. Coffey RJ, Richards JS, Remmert CS, LeRoy SS, Schoville RR, Baldwin PJ. An introduction to critical paths. Qual Manag Health Care 1992;1:45-54.

39. Marrie TJ, Lau CY, Wheeler SL, Wong CJ, Vanervoort MK, Feagan BG. A controlled trial of a critical pathway for treatment of community-acquired pneumonia. CAPITAL Study Investigators. Community-Acquired Pneumonia Intervention Trial Assessing Levofloxacin. JAMA 2000;283:749-55. 